\title{
The Influence Law of Stress Level for Shear Displacement of Intact
}

\section{Loess}

\author{
Kangfeng Yuana \\ (Shanxi Provincial Research Institute of Communications, Shanxi Key Laboratory of Geotechnical \\ and Underground Engineering, Shanxi, Taiyuan 030006) \\ ayuankangfeng@163.com
}

Key words: Shear displacement; Stress level; Intact loess; Water content; Vertical pressure

Abstract. At present, the research is not enough for the shear displacement and stress level in domestic. The paper aims how the law between the shear displacement and stress level by shear test for intact loess. The results showed that: with the increasing of stress level, the relationship curves of shear displacement gradually increased for the same vertical pressure. The sample of displacement curve can be divided into three stages. Which are slow development stage, rapid development stage and deformation stability phase.

\section{Introduction}

Loess special sensitivity to water and the constitutive relation,deformation, strength has always been the research center of loess mechanic characteristic.In recent years, there are more and more depth study of loess deformation characteristics.And has obtained certain achievement. ZHANG Jun-hong et al ${ }^{[1]}$ propose that the author through analyzing stress-strain relationship finds that the structure and intensity were mainly affected by factors like primitive water content, surrounding pressure and density which determine the stress-strain relationship and destruction formation. CAO Xiao-ping et al ${ }^{[2]}$ think that the result have some diversity tested by different experiment.

Furthermore, the result tested in situ is great than the tested indoor. Especially the strain of shear damaged, the result of the same loess tested in situ is $2 \sim 2.5$ times to the indoors. Feng Wang et al ${ }^{[3]}$ in the process of drainage, freeness of water is firstly enlarged and then diminished as the increasing of plane void ratio. But in the process of water absorption, freeness of water is firstly enlarged and secondly diminished and enlarged again as the increasing of plane void ratio. The corresponding plane void ratio of maximum drainage and water absorbing capacity is different. However, In the previous research work, the study of evolvement law of the loess humidifying shear have less research ${ }^{[4]-[10]}$.

With the help of shear tests to research the characteristics of intact loess for different stress level and different pressure, coming up with some conclusions. The research have certain theoretical significance for the study of loess shear properties. At the same time, it provides reference for the future research of intact loess.

\section{The loess of test}

The loess of tests is taken from certain foundation at the Jinnan district, in a depth of $6 \mathrm{~m}$ 
below the surface, which is brownish yellow, silty clay, soil evenly, with a small amount of worm holes. The soil samples have been whittled to length $35 \mathrm{~cm} \sim 45 \mathrm{~cm}$ cube in the field, with the plastic wrapped well and indicated the vertical direction, transported back to the laboratory.The natural moisture content of soil samples was $9.5 \%$, through the burette method to configure the required moisture content for the sample.

\section{Test Instruments and Test Method}

\section{Test Instruments}

The test instrument is the conventional direct shear apparatu which come from a Nanjing experimental instrument factory. Through the improvement of instrument application,make the strain type apparatu into stress type, which can realize some stress conditions of humidifying direct shear test.Through adding the flowmeter which can guarantee to the required water content.

\section{Test Method}

Prepare eight original state compression sample (diameter $6.03 \mathrm{~cm}$, height $2 \mathrm{~cm}$ ). The vertical pressure of test is $200 \mathrm{kpa}$ and $400 \mathrm{kpa}$, with the humidifying direct shear test to measure the law of shear displacement and moisture content.Installed the vertical load, until the need of the vertical pressure, compression after stability, start the motor, began to shear and shear stress at a certain stress of $0.3,0.4,0.5,0.6$ times of the stress level. In the process of shearing by stepper motor to maintain a constant shear stress, immersed in a certain shear stress under the gradation of shear test, calculate water to $10 \%, 12 \%, 14 \%, 16 \%$ when the required water. And then in the process of shearing by water flooding until sample shear failure or shear stability.The stability criteria for shear displacement increment is less $0.01 \mathrm{~mm}$ for ten minutes.

\section{Test Results and Analysis}

In the condition of the vertical pressure $200 \mathrm{kpa}$, the affect law of different stress level for shear displacement is indicated in figures 1 to 4 :
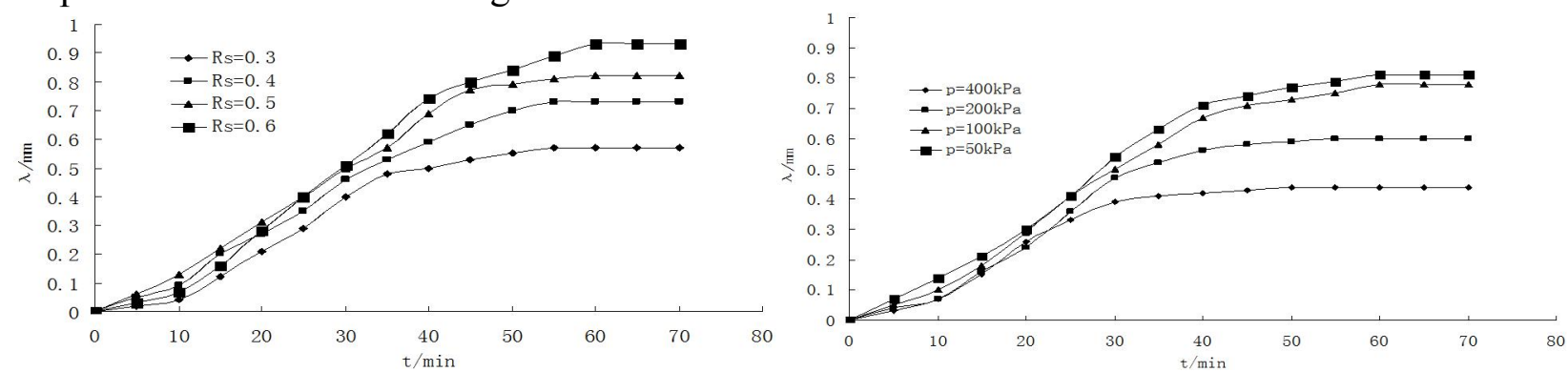

Figure 1.The shear curve for $\mathrm{w}=8 \%$ to $\mathrm{w}=10 \%$
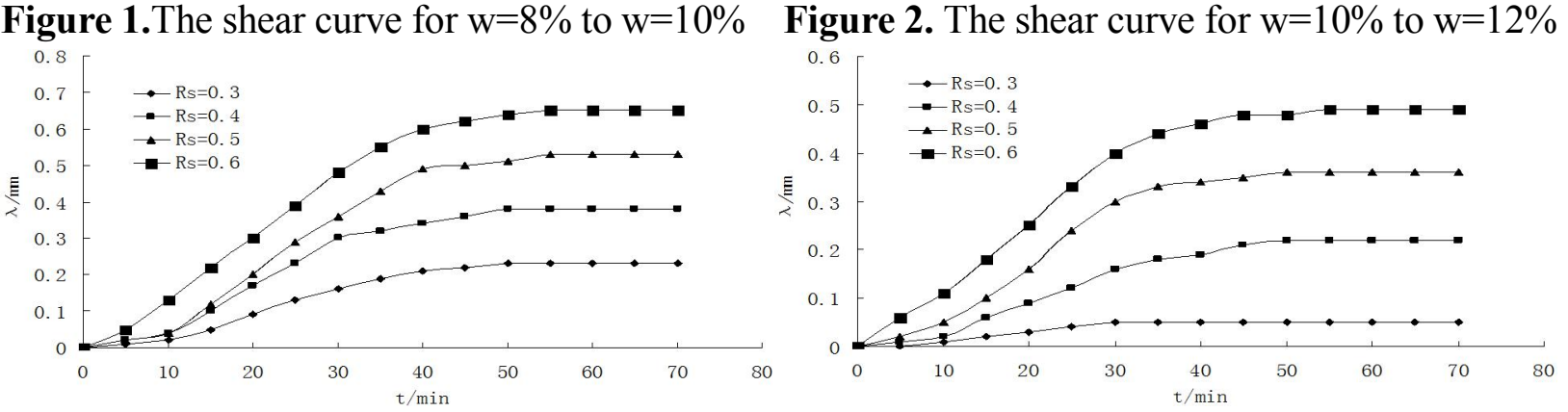

Figure 3. The shear curve for $\mathrm{w}=12 \%$ to $\mathrm{w}=14 \%$

Figure 4. The shear curve for $\mathrm{w}=14 \%$ to $\mathrm{w}=16 \%$ 
Figure 1-4 shows that with the increasing of stress level, the relationship curves of shear displacement gradually increased for the same vertical pressure.

In the condition of the vertical pressure $400 \mathrm{kpa}$, the affect law of different water content for shear displacement is indicated in figures 5 to 8 :
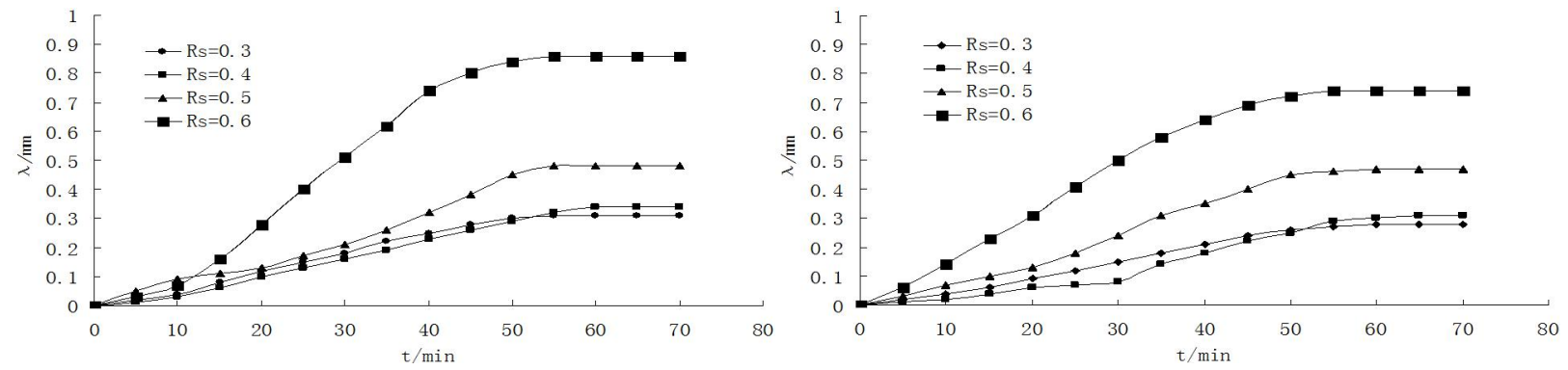

Figure 5. The shear curve for $\mathrm{w}=8 \%$ to $\mathrm{w}=10 \%$

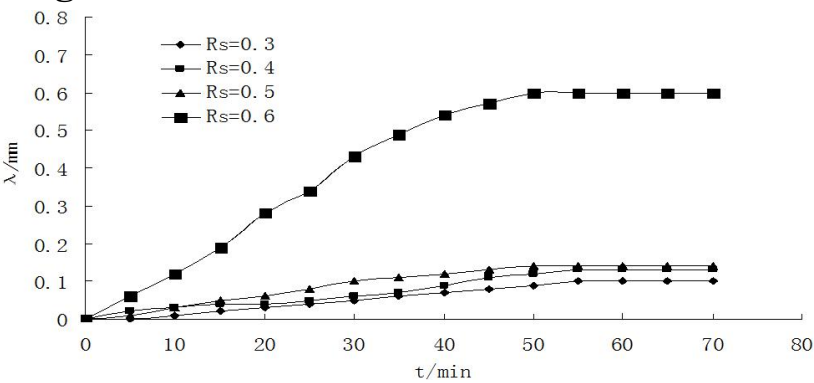

Figure 6. The shear curve for $\mathrm{w}=10 \%$ to $\mathrm{w}=12 \%$

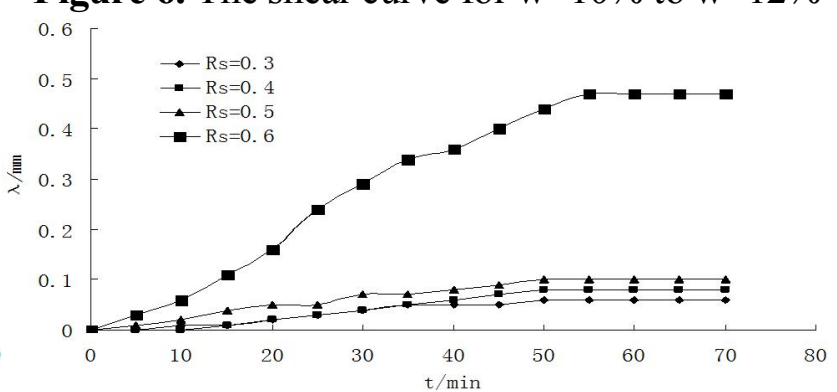

Figure 7. The shear curve for $\mathrm{w}=12 \%$ to $\mathrm{w}=14 \%$

Figure 8. The shear curve for $\mathrm{w}=14 \%$ to $\mathrm{w}=16 \%$

Figure 5-8 shows that the sample of displacement curve can be divided into three stages. Which are slow development stage, rapid development stage and deformation stability phase.

\section{Conclusions}

In this paper, direct shear apparatu is applied to study shear properties of intact loess. The main conclusions are as follows:

(1) With the increasing of stress level, the relationship curves of shear displacement gradually increased for the same vertical pressure.

(2) The sample of displacement curve can be divided into three stages. Which are slow development stage, rapid development stage and deformation stability phase.

\section{Acknowledgements}

The paper is Sponsored by the Basic Research Project of Shanxi Province [2014021033-2].

\section{References}

[1] ZHANG Jun-hong,SHI Xu-chao,ZHANG Xin-juan.The Study on Experiment of Ocher's Water Content to Structure Effect [J].HENAN SCIENCE,2010,28(12):1575-1578(in Chinese).

[2] CAO Xiao-ping,LI Bao-xiong, YAN Song-hong. Influence of loessmechanicalparameter by different experimentations[J].HYDROGEOLOGY\& ENGINEERING GEOLOGY, 2010, 37(1):80-84 (in Chinese).

[3] FENG Wang LI Shun-qun, ZHANG Yan. Relationship between microstructure and soil-water characteristic of different density clay [J]. Journal of Liaoning Technical University（Natural Science ), 2013,32(5):611-614 (in Chinese). 
[4] SONG Fei. The study on the stability and deformation mechanism of huazicun loess landslide [J].SHANXI SCIENCE \& TECHNOLOGY of COMMUNICATIONS, 2012, 216(3):13-15 (in Chinese).

[5] LI Xu-hua.The Rational Slope Type Research on Loess High Slope [J].SHANXI SCIENCE \& TECHNOLOGY of COMMUNICATIONS, 2012,214(1):29-30 (in Chinese).

[6] LIAO Xiong-hua, WANG Lei-xiao, ZHANG Ke-xu et,al. An inelasto-plastic constitutive model for soil[J]. Rock and Soil Mechanics, 2002(1):41-45 (in Chinese).

[7] TANG Xin-fu, ZHAO Yun-gang. Effects of Moisture Content on the Shear Strength of a Compacted Clay [J].Metal materials and metallurgy engineering,2009,37(3):49-53(in Chinese).

[8] Zhang Lizhong, Hu Ruilin, Li Xiangquan, et al. Soil microstructure quantitative analysis system and its application[J].Geological Scienceand Technology Information, 2008, 27(1): 108-112 (in Chinese).

[9] SHENG Wei-gao,LI Guo-wei,YUAN Jun-ping. Stability analysis of high slopes based on the influence of water content change on soil strength [J]. Advances in Science and Technology of Water Resources, 2009,29(1):12-15 (in Chinese).

[10] Wang Gaigai,Zhang Yulong,Yu Na.Spatial variability of water retention capability in aeolian sandy soil and its pedotransfer function[J].Journal of Liaoning Technical University: Natural Science,2012,31(3):366-369 (in Chinese). 